\title{
Penerapan Data Mining Untuk Menganalisis Data Mahasiswa Baru STIE-GK Muara Bulian
}

\author{
Azwar Anas ${ }^{1}$, Ratumas Hartha Delima ${ }^{2}$ \\ Manajemen, STIE - Graha Karya Muara Bulian \\ Jl. Gajah Mada, Muara Bulian, Indonesia \\ azwarzayn@gmail.com_artharatu95@gmail.com²
}

\begin{abstract}
Data that accumulates over time will have no value if it is not analyzed. To analyze historical data, it is necessary to use the right method. Data mining or in other terms Data Mining is the right solution to analyze the historical data. It is the pile of data that wants to be analyzed in this study using data mining techniques. The purpose of this study was to find the pattern of new students at STIE-GK Muara Bulian for the 2021/2022 academic year. In this study, the author uses data mining enrichment techniques. The algorithm that the author uses in this data mining is the Apriori Algorithm. While the software used is Weka Data Mining. Tests using Weka data mining software get the 10 best rules. By focusing on the subdistricts of origin of the new students, the combination obtained is If the new student does not come from Pemayung and Bajubang sub-districts as many as 1 person, then also does not come from Maro Sebo Ulu District as many as 73 people with a $90 \%$ confidence level.
\end{abstract}

Keywords: apriori, students, districts, mining.

\begin{abstract}
Abstrak
Data yang menumpuk dari waktu ke waktu, tidak akan memiliki nilai yang berharga jika tidak dilakukan analisis. Untuk menganalisis data historis, maka perlu digunakan metode yang tepat. Penambangan data atau dalam istilah lainnya Data Mining merupakan solusi yang tepat untuk menganalisis data historis tersebut. Tumpukan data tersebutlah yang hendak dianalisis dalam penelitian ini dengan teknik penambangan data. Tujuan dari penelitian ini adalah untuk mendapatkan pola mahasiswa baru STIE-GK Muara Bulian tahun akademik 2021/2022. Dalam penelitian ini, penulis menggunakan teknik pengayaan data mining. Adapun algoritma yang penulis gunakan dalam penambangan data ini adalah Algoritma Apriori. Sedangkan software yang digunakan adalah Weka Data Mining. Pengujian menggunakan software data mining Weka didapatkan 10 rule terbaik. Dengan fokus pada kecamatan asal mahasiswa baru tersebut, maka kombinasi yang didapat adalah Jika mahasiswa baru tidak berasal dari Kecamatan Pemayung dan Bajubang sebanyak 1 orang, maka juga tidak berasal dari Kecamatan Maro Sebo Ulu sebanyak 73 orang dengan tingkat confidence $90 \%$.
\end{abstract}

Kata kunci: apriori, mahasiswa, kecamatan, penambangan

\section{Pendahuluan}

Perguruan Tinggi merupakan lembaga pendidikan tinggi yang memberikan kontribusi besar bagi negara dalam usaha mencerdaskan kehidupan bangsa. Input dari setiap perguruan tinggi adalah mahasiswa. Pada prosesnya, mahasiswa melakukan pendaftaran, proses pembelajaran, penelitian dan pengabdian kepada masyarakat atau yang lebih dikenal dengan Tri Darma Perguruan Tinggi, hingga dinyatakan lulus. Secara umum, perguruan tinggi di Indonesia dikategorikan menjadi dua, yaitu Perguruan Tinggi Negeri (PTN) dan Perguruan Tinggi Swasta (PTS). PTN merupakan PT di bawah naungan pemerintah, sedangkan PTS berada di bawah naungan yayasan atau kelompok masyarakat.

PTN dengan pengelolaan dari pemerintah, maka segala biaya operasionalnya pun ditanggung oleh pemerintah/Negara. Sehingga tidak heran jika PTN lebih leluasa dalam melaksanakan berbagai kegiatan terutama Tri Darma Perguruan Tinggi. Berbeda halnya dengan PTS yang hanya mengandalkan biaya operasional dari jumlah mahasiswa yang terdaftar. Sehingga hampir setiap PTS berlomba-lomba untuk merekrut sebanyak-banyaknya calon mahasiswa barunya. Berbagai cara dilakukan oleh tim promosi PTS, mulai dari biaya pendaftaran yang rendah bahkan gratis, biaya pembangunan yang bisa dicicil hingga imingiming pemberian beasiswa dari berbagai sumber.

Sekolah Tinggi Ilmu Ekonomi-Graha Karya (STIE-GK) Muara Bulian merupakan PTS yang ada di Kabupaten Batanghari. Sebagaimana PTS lainnya, STIE-GK Muara Bulian setiap tahun akademik melakukan proses penerimaan mahasiswa baru. STIE-GK Muara Bulian telah berdiri sejak tahun 2000, artinya kini telah berusia 
21 tahun. Maka dengan kegiatan penerimaan mahasiswa baru secara rutin setiap tahunnya, terjadilah penumpukan data yang menjadi data historis bagi institusi ini. Data yang menumpuk dari waktu ke waktu, tidak akan memiliki nilai yang berharga jika tidak dilakukan analisis. Untuk menganalisis data historis, maka perlu digunakan metode yang tepat. Penambangan data atau dalam istilah lainnya Data Mining merupakan solusi yang tepat untuk menganalisis data historis tersebut.

Data mining terdiri dari dua kata yaitu data dan mining. Data adalah sekumpulan bahan, alat, teks yang belum mempunyai arti. Biasanya data bersifat tunggal dan kaku. Butuh proses pengolahan yang benar untuk menghasilkan data menjadi informasi. Secara bahasa mining berarti. Data mining adalah suatu proses penambangan data menjadi suatu informasi yang bernilai. Data mining juga disebut dengan proses yang digunakan untuk menggali penemuan pengetahuan di dalam sebuah database[1].

Knowledge Discovery from Data atau (KDD), yaitu proses yang sistematis sebagai berikut[2]:

1. Data Cleaning adalah Proses pembersihan data dari kesalahan data dan data yang tidak konsisten.

2. Data Integration adalah Proses untuk penggabungan data dari beberapa sumber.

3. Data Selection adalah Proses untuk pemilihan data dari basis data yang sesuai dengan tujuan analisa.

4. Data Transformation adalah Proses pengubahan bentuk data menjadi data yang diinginkan.

5. Data Mining adalah Proses penting yang menggunakan sebuah metode tertentu mendapatkan pengetahuan dari sekumpulan data.

6. Pattern Evaluation adalah Proses mengidentifikasi hasil pengolahan data.

7. Knowledge Presentation adalah proses merepresentasikan informasi yang dibutuhkan, proses dimana informasi yang telah didapatkan kemudian digunakan oleh pemilik data.

Tumpukan data penerimaan mahasiswa baru STIE-GK Muara Bulian yang akan dianalisis adalah berdasarkan data formulir yang telah diisi oleh calon mahasiswa baru tahun akademik 2021/2022. Jumlah data yang dianalisis adalah 100 orang mahasiswa baru yang terdiri dari program studi Manajemen dan Akuntansi. Fokus data yang dianalisis untuk kemudian didapatkan polanya adalah data Jenis Kelamin, Pilihan Kelas, Desa dan Pilihan Program Studi.

Sesuai dengan fokus data di atas, maka algoritma data mining yang digunakan dalam menganalisis data tersebut adalah menggunakan Algoritma Apriori. Algoritma apriori adalah algoritma yang digunakan untuk proses pencarian data berulang dengan menggunakan teknik rule asosisasi atau association rule. Algortima apriori menggunakan data frekuensi tinggi yang telah ada sebelumnya untuk diproses menjadi informasi selanjutnya. Pada algoritma apriori, menentukan kandidat yang mungkin muncul dengan cara memperhatikan minimum support dan minimum confidence. Support adalah nilai penunjang atau persentase kombinasi sebuah item dalam suatu database[3].

Association rule merupakan teknik data mining untuk mencari pola hubungan dalam data atau basis data. Teknik yang paling sering digunakan adalah market basket analysis (MBA). Teknik MBA ini digunakan untuk mencari pelanggan yang membeli barang pada toko X, akan membeli barang Y dan seterusnya[4].

Tabel 1. Contoh Transaksi untuk Association Rule Analysis

\begin{tabular}{cc}
\hline Trans & Itemset \\
\hline 1 & $\mathrm{~A}, \mathrm{~B}, \mathrm{E}$ \\
2 & $\mathrm{~B}, \mathrm{D}$ \\
3 & $\mathrm{~B}, \mathrm{C}$ \\
4 & $\mathrm{~A}, \mathrm{~B}, \mathrm{D}$ \\
5 & $\mathrm{~A}, \mathrm{C}$ \\
6 & $\mathrm{~B}, \mathrm{C}$ \\
7 & $\mathrm{~A}, \mathrm{C}$ \\
8 & $\mathrm{~A}, \mathrm{~B}, \mathrm{C}, \mathrm{E}$ \\
9 & $\mathrm{~A}, \mathrm{~B}, \mathrm{C}$ \\
\hline
\end{tabular}

Pada tabel di atas itemset adalah jenis barang yang dibeli pada toko tersebut, trans adalah kode transaksi atau urutan pelanggan yang bertransaksi. Pada tabel tersebut dapat dilihat pada transaksi pertama barang yang dibeli adalah A, B dan E. Transaksi kedua barang yang dibeli adalah B dan D, begitu seterusnya. Analisis asosiasi akan melakukan analisis hubungan dengan aturan tertentu yang sering disebut sebagai association rule. 
Support dan confidence dapat dihitung sebagai berikut [5]:

Support, $s(\mathrm{X} \rightarrow \mathrm{Y})=\frac{\sigma(\mathrm{XUY})}{\mathrm{N}}$

Confidence, $c(\mathrm{X} \rightarrow \mathrm{Y})=\frac{\sigma(\mathrm{XUY})}{\sigma \mathrm{X}}$

Di mana X dan Y sebagai itemset dan $\sigma$ adalah support dari itemset.

Adapun penelitian terdahulu yang berkaitan dengan penelitian ini diantaranya:

1. Penggunaan Algorithma Apriori Untuk Mengetahui Tingkat Kesetiaan Konsumen[6]. Data yang diolah pada penelitian ini adalah Kategori profesi, jenis kelamin konsumen dan merek kenderaan bermotor di ukur dengan parameter pada tingkat ketertarikan konsumen terhadap merek kenderaan yang di sajikan. Algoritma yang digunakan adalah algoritma apriori, informasi yang ditampilkan berupa nilai support dan confidence dari masing-masing kategori.

2. Implementasi Algoritma Apriori Dalam Menentukan Penjualan Mobil Yang Paling Diminati Pada [7]. Hasil penelitian menunjukkan bahwa penjualan mobil Honda yang paling diminati konsumen adalah Mobil Brio Satya, HRV, Mobillio, Jazz, dan CRV.

3. Implementasi Algoritma Apriori Untuk Menentukan Stok Obat[8]. Kesimpulan pada penelitian ini adalah jika membeli amlodipine $5 \mathrm{mg}$ maka akan membeli sanmol hal ini didapat dari support 33,33\% dan confidence 66,66 \%, jika membeli amoxan $500 \mathrm{mg}$ maka akan membeli sanmol dengan nilai support $41,66 \%$ dan confidence $71,42 \%$ dan jika membeli sanmol maka akan membeli amoxan $500 \mathrm{mg}$ dengan nilai support $41,66 \%$ dan confidence $62,50 \%$.

4. Implementasi Data Mining Pada Penjualan Produk Elektronik Dengan Algoritma Apriori (Studi Kasus : Kreditplus)[9]. Hasil penelitian menunjukkan merek produk elektronik yang paling banyak terjual adalah Acer dan Toshiba, dengan diketahuinya produk yang paling banyak terjual tersebut, sehingga perusahaan dapat menyusun strategi pemasaran untuk memasarkan produk dengan merek lain dengan meneliti apa kelebihan produk yang paling banyak terjual.

5. Implementasi Data Mining Penjualan Produk Kosmetik [10]. Pola asosiasi yang terbentuk dengan nilai minimum support $10 \%$ dan nilai minimum confidence $50 \%$ menghasilkan 7 aturan asosiasi. Dan strong rules yang didapatkan adalah Jika membeli CHARCO maka akan membeli EBS dengan nilai support $15.5 \%$ dan nilai minimum confidence $61.4 \%$.

\section{Metode Penelitian}

\subsection{Metode Penelitian}

Metode yang penulis gunakan dalam penelitian ini adalah penelitian labor. Dalam penelitian labor ini, penulis menggunakan teknik pengayaan data mining. Adapun algoritma yang penulis gunakan dalam penambangan data ini adalah Algoritma Apriori. Sedangkan software yang digunakan adalah Weka Data Mining. Dalam melakukan sebuah penelitian, peneliti harus mengikuti tahapan-tahapan yang sistematis, agar hasil penelitian tidak keluar dari apa yang diharapkan.

\subsection{Kerangka Penelitian}

Pada bagian ini akan diuraikan kerangka penelitian, kerangka ini merupakan langkah-langkah yang akan dilakukan dalam penyelesaian masalah yang akan dibahas. 


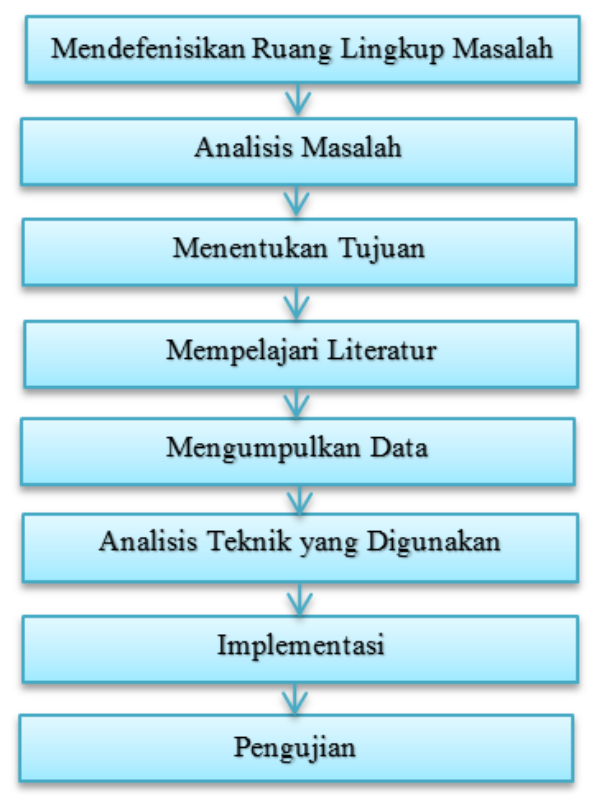

Gambar 1. Kerangka Penelitian

Berdasarkan kerangka pada gambar 1. maka masing-masing langkahnya dapat diuraikan seperti berikut ini :

1. Mendefinisikan Ruang Lingkup Masalah

Ruang lingkup masalah yang akan diteliti harus ditentukan terlebih dahulu, karena tanpa mampu menentukan serta mendefinisikan batasan masalah yang akan diteliti, maka tidak akan pernah didapat suatu solusi yang terbaik dari masalah tersebut. Jadi langkah pertama ini adalah langkah awal yang terpenting dalam penulisan ini.

2. Analisis Masalah

Langkah analisis masalah adalah untuk dapat memahami masalah yang telah ditentukan ruang lingkup atau batasannya. Dengan menganalisa masalah yang telah ditentukan tersebut, maka diharapkan masalah dapat dipahami dengan baik. Pada bagian ini digambarkan proses untuk mendapatkan pola pembimbing skripsi menggunakan algoritma apriori. Disamping itu juga diuraikan tentang kebutuhan data untuk menggali kaidah asosiasi. Dari hasil analisis tersebut, maka algoritma apriori hendaknya mampu menampilkan pola mahasiswa baru tersebut dengan baik.

3. Penentuan Tujuan

Berdasarkan pemahaman dari masalah, maka ditentukan tujuan yang akan dicapai dari penulisan ini. Pada tujuan ini ditentukan target yang dicapai, terutama yang dapat mengatasi masalah-masalah yang ada.

4. Mempelajari Literatur

Untuk mencapai tujuan, maka dipelajari berbagai literatur yang relevan dengna masalah yang diteliti. Kemudian literatur-literatur yang dipelajari tersebut diseleksi untuk dapat ditentukan literatur-literatur mana yang akan digunakan dalam penelitian. Literatur diambil dari internet, yang berupa artikel dan jurnal ilmiah tentang data mining, association rule dan algoritma apriori, serta bahan bacaan lain yang mendukung penelitian.

5. Pengumpulan Data dan Informasi

Dalam pengumpulan data dilakukan observasi yaitu pengamatan secara langsung di tempat penelitian sehingga permasalahan yang ada dapat diketahui dengan jelas. Kemudian dilakukan interview yang bertujuan untuk mendapatkan informasi atau data yang dibutuhkan. Selain itu juga dilakukan studi kepustakaan yaitu dengan membaca buku-buku yang menunjang dalam melakukan analisa terhadap data dan informasi yang didapat. Adapun data-data yang diperlukan dalam penelitian ini adalah data mahasiswa baru STIE-GK Muara Bulian.

6. Analisis Teknik yang digunakan

Bagian ini bertujuan untuk menganalisis dan memahami teknik yang akan digunakan dalam pengolahan data yang telah diperoleh dari tempat penelitian, terutama pada proses, yang mana teknik yang digunakan untuk pengolahan data dengan algoritma apriori.

7. Implementasi

Tahapan implementasi adalah penerapan algoritma pada software data mining Weka. Hal ini dilakukan agar algoritma yang digunakan sesuai dengan data yang ada. 
8. Pengujian

Pengujian dilakukan untuk melihat perbandingan antara perhitungan manual dengan proses pada software data mining yang digunakan yaitu Weka.

\section{Hasil Penelitian}

\subsection{Pemrosesan Data menggunakan Algoritma Apriori}

Dalam penelitian ini, penulis melakukan analisis terhadap 100 data mahasiswa baru tahun akademik 2021/2022 STIE-GK Muara Bulian. Penulis melakukan analisis terhadap data mahasiswa baru tersebut. Data tersebut di atas dapat dilihat pada tabel berikut.

Tabel 2. Data Mahasiswa Baru

\begin{tabular}{|c|c|c|c|c|c|c|c|c|c|c|c|c|}
\hline \multirow{2}{*}{ NO } & \multicolumn{2}{|c|}{ JEKEL } & \multicolumn{2}{|c|}{ KELAS } & \multicolumn{8}{|c|}{ KECAMATAN } \\
\hline & $\mathbf{L}$ & $\mathbf{P}$ & $\mathbf{A}$ & B & MBL & PMY & ВJB & MTS & MRS & MSI & MSU & BTN \\
\hline 1 & $\mathrm{Y}$ & $\mathrm{T}$ & $\mathrm{Y}$ & $\mathrm{T}$ & $\mathrm{Y}$ & $\mathrm{T}$ & $\mathrm{T}$ & $\mathrm{T}$ & $\mathrm{T}$ & $\mathrm{T}$ & $\mathrm{T}$ & $\mathrm{T}$ \\
\hline 2 & $\mathrm{Y}$ & $\mathrm{T}$ & $\mathrm{T}$ & $\mathrm{Y}$ & $\mathrm{T}$ & $\mathrm{T}$ & $\mathrm{T}$ & $\mathrm{T}$ & $\mathrm{Y}$ & $\mathrm{T}$ & $\mathrm{T}$ & $\mathrm{T}$ \\
\hline 3 & $\mathrm{Y}$ & $\mathrm{T}$ & $\mathrm{T}$ & $\mathrm{Y}$ & $\mathrm{T}$ & $\mathrm{T}$ & $\mathrm{T}$ & $\mathrm{T}$ & $\mathrm{T}$ & $\mathrm{T}$ & $\mathrm{T}$ & $\mathrm{Y}$ \\
\hline 4 & $\mathrm{~T}$ & $\mathrm{Y}$ & $\mathrm{T}$ & $\mathrm{Y}$ & Y & $\mathrm{T}$ & $\mathrm{T}$ & $\mathrm{T}$ & $\mathrm{T}$ & $\mathrm{T}$ & $\mathrm{T}$ & $\mathrm{T}$ \\
\hline 5 & $\mathrm{~T}$ & $\mathrm{Y}$ & $\mathrm{Y}$ & $\mathrm{T}$ & $\mathrm{T}$ & $\mathrm{T}$ & $\mathrm{T}$ & $\mathrm{Y}$ & $\mathrm{T}$ & $\mathrm{T}$ & $\mathrm{T}$ & $\mathrm{T}$ \\
\hline 6 & $\mathrm{~T}$ & $\mathrm{Y}$ & $\mathrm{Y}$ & $\mathrm{T}$ & $\mathrm{T}$ & $\mathrm{T}$ & $\mathrm{T}$ & $\mathrm{T}$ & $\mathrm{T}$ & $\mathrm{Y}$ & $\mathrm{T}$ & $\mathrm{T}$ \\
\hline 7 & $\mathrm{~T}$ & $\mathrm{Y}$ & $\mathrm{Y}$ & $\mathrm{T}$ & Y & $\mathrm{T}$ & $\mathrm{T}$ & $\mathrm{T}$ & $\mathrm{T}$ & $\mathrm{T}$ & $\mathrm{T}$ & $\mathrm{T}$ \\
\hline 8 & $\mathrm{~T}$ & $\mathrm{Y}$ & $\mathrm{Y}$ & $\mathrm{T}$ & $\mathrm{T}$ & $\mathrm{T}$ & $\mathrm{T}$ & $\mathrm{T}$ & $\mathrm{Y}$ & $\mathrm{T}$ & $\mathrm{T}$ & $\mathrm{T}$ \\
\hline 9 & $\mathrm{~T}$ & $\mathrm{Y}$ & $\mathrm{Y}$ & $\mathrm{T}$ & $\mathrm{T}$ & $\mathrm{T}$ & $\mathrm{T}$ & $\mathrm{T}$ & $\mathrm{T}$ & $\mathrm{T}$ & $\mathrm{T}$ & $\mathrm{Y}$ \\
\hline 10 & $\mathrm{~T}$ & $\mathrm{Y}$ & $\mathrm{Y}$ & $\mathrm{T}$ & $\mathrm{Y}$ & $\mathrm{T}$ & $\mathrm{T}$ & $\mathrm{T}$ & $\mathrm{T}$ & $\mathrm{T}$ & $\mathrm{T}$ & $\mathrm{T}$ \\
\hline 11 & $\mathrm{Y}$ & $\mathrm{T}$ & $\mathrm{T}$ & $\mathrm{Y}$ & $\mathrm{T}$ & $\mathrm{T}$ & $\mathrm{T}$ & Y & $\mathrm{T}$ & $\mathrm{T}$ & $\mathrm{T}$ & $\mathrm{T}$ \\
\hline 12 & $\mathrm{Y}$ & $\mathrm{T}$ & $\mathrm{T}$ & $\mathrm{Y}$ & $\mathrm{T}$ & $\mathrm{T}$ & $\mathrm{T}$ & $\mathrm{T}$ & $\mathrm{T}$ & $\mathrm{Y}$ & $\mathrm{T}$ & $\mathrm{T}$ \\
\hline 13 & $\mathrm{Y}$ & $\mathrm{T}$ & $\mathrm{T}$ & $\mathrm{Y}$ & $\mathrm{T}$ & Y & $\mathrm{T}$ & $\mathrm{T}$ & $\mathrm{T}$ & $\mathrm{T}$ & $\mathrm{T}$ & $\mathrm{T}$ \\
\hline 14 & $\mathrm{Y}$ & $\mathrm{T}$ & $\mathrm{T}$ & $\mathrm{Y}$ & $\mathrm{T}$ & $\mathrm{T}$ & Y & $\mathrm{T}$ & $\mathrm{T}$ & $\mathrm{T}$ & $\mathrm{T}$ & $\mathrm{T}$ \\
\hline 15 & $\mathrm{Y}$ & $\mathrm{T}$ & $\mathrm{Y}$ & $\mathrm{T}$ & $\mathrm{T}$ & $\mathrm{T}$ & $\mathrm{T}$ & $\mathrm{T}$ & $\mathrm{T}$ & $\mathrm{T}$ & $\mathrm{Y}$ & $\mathrm{T}$ \\
\hline 16 & $\mathrm{Y}$ & $\mathrm{T}$ & $\mathrm{Y}$ & $\mathrm{T}$ & $\mathrm{T}$ & $\mathrm{T}$ & $\mathrm{T}$ & $\mathrm{T}$ & Y & $\mathrm{T}$ & $\mathrm{T}$ & $\mathrm{T}$ \\
\hline 17 & $\mathrm{~T}$ & $\mathrm{Y}$ & $\mathrm{Y}$ & $\mathrm{T}$ & $\mathrm{T}$ & $\mathrm{T}$ & $\mathrm{T}$ & $\mathrm{T}$ & $\mathrm{T}$ & $\mathrm{T}$ & $\mathrm{T}$ & $\mathrm{Y}$ \\
\hline 18 & $\mathrm{~T}$ & $\mathrm{Y}$ & $\mathrm{Y}$ & $\mathrm{T}$ & $\mathrm{Y}$ & $\mathrm{T}$ & $\mathrm{T}$ & $\mathrm{T}$ & $\mathrm{T}$ & $\mathrm{T}$ & $\mathrm{T}$ & $\mathrm{T}$ \\
\hline 19 & $\mathrm{~T}$ & $\mathrm{Y}$ & $\mathrm{T}$ & $\mathrm{Y}$ & $\mathrm{T}$ & $\mathrm{T}$ & $\mathrm{T}$ & Y & $\mathrm{T}$ & $\mathrm{T}$ & $\mathrm{T}$ & $\mathrm{T}$ \\
\hline 20 & $\mathrm{~T}$ & $\mathrm{Y}$ & $\mathrm{T}$ & $\mathrm{Y}$ & $\mathrm{T}$ & $\mathrm{T}$ & $\mathrm{T}$ & $\mathrm{T}$ & $\mathrm{T}$ & $\mathrm{Y}$ & $\mathrm{T}$ & $\mathrm{T}$ \\
\hline 21 & $\mathrm{Y}$ & $\mathrm{T}$ & $\mathrm{Y}$ & $\mathrm{T}$ & $\mathrm{T}$ & Y & $\mathrm{T}$ & $\mathrm{T}$ & $\mathrm{T}$ & $\mathrm{T}$ & $\mathrm{T}$ & $\mathrm{T}$ \\
\hline 22 & $\mathrm{Y}$ & $\mathrm{T}$ & $\mathrm{Y}$ & $\mathrm{T}$ & $\mathrm{T}$ & $\mathrm{T}$ & Y & $\mathrm{T}$ & $\mathrm{T}$ & $\mathrm{T}$ & $\mathrm{T}$ & $\mathrm{T}$ \\
\hline 23 & $\mathrm{Y}$ & $\mathrm{T}$ & $\mathrm{Y}$ & $\mathrm{T}$ & $\mathrm{T}$ & $\mathrm{T}$ & $\mathrm{T}$ & $\mathrm{T}$ & $\mathrm{T}$ & $\mathrm{T}$ & $\mathrm{Y}$ & $\mathrm{T}$ \\
\hline 24 & $\mathrm{Y}$ & $\mathrm{T}$ & $\mathrm{Y}$ & $\mathrm{T}$ & $\mathrm{T}$ & $\mathrm{T}$ & $\mathrm{T}$ & Y & $\mathrm{T}$ & $\mathrm{T}$ & $\mathrm{T}$ & $\mathrm{T}$ \\
\hline 25 & $\mathrm{~T}$ & $\mathrm{Y}$ & $\mathrm{T}$ & $\mathrm{Y}$ & $\mathrm{T}$ & $\mathrm{T}$ & $\mathrm{T}$ & $\mathrm{T}$ & $\mathrm{T}$ & $\mathrm{Y}$ & $\mathrm{T}$ & $\mathrm{T}$ \\
\hline 26 & $\mathrm{~T}$ & $\mathrm{Y}$ & $\mathrm{T}$ & $\mathrm{Y}$ & $\mathrm{Y}$ & $\mathrm{T}$ & $\mathrm{T}$ & $\mathrm{T}$ & $\mathrm{T}$ & $\mathrm{T}$ & $\mathrm{T}$ & $\mathrm{T}$ \\
\hline 27 & $\mathrm{Y}$ & $\mathrm{T}$ & $\mathrm{T}$ & $\mathrm{Y}$ & $\mathrm{T}$ & $\mathrm{T}$ & $\mathrm{T}$ & $\mathrm{T}$ & Y & $\mathrm{T}$ & $\mathrm{T}$ & $\mathrm{T}$ \\
\hline 28 & $\mathrm{Y}$ & $\mathrm{T}$ & $\mathrm{Y}$ & $\mathrm{T}$ & $\mathrm{T}$ & $\mathrm{T}$ & $\mathrm{T}$ & $\mathrm{T}$ & $\mathrm{T}$ & $\mathrm{T}$ & $\mathrm{T}$ & $\mathrm{Y}$ \\
\hline 29 & $\mathrm{Y}$ & $\mathrm{T}$ & $\mathrm{Y}$ & $\mathrm{T}$ & Y & $\mathrm{T}$ & $\mathrm{T}$ & $\mathrm{T}$ & $\mathrm{T}$ & $\mathrm{T}$ & $\mathrm{T}$ & $\mathrm{T}$ \\
\hline 30 & $\mathrm{Y}$ & $\mathrm{T}$ & $\mathrm{Y}$ & $\mathrm{T}$ & $\mathrm{T}$ & $\mathrm{T}$ & $\mathrm{T}$ & Y & $\mathrm{T}$ & $\mathrm{T}$ & $\mathrm{T}$ & $\mathrm{T}$ \\
\hline 31 & $\mathrm{~T}$ & $\mathrm{Y}$ & $\mathrm{Y}$ & $\mathrm{T}$ & $\mathrm{T}$ & $\mathrm{T}$ & $\mathrm{T}$ & $\mathrm{T}$ & $\mathrm{T}$ & $\mathrm{Y}$ & $\mathrm{T}$ & $\mathrm{T}$ \\
\hline 32 & $\mathrm{~T}$ & $\mathrm{Y}$ & $\mathrm{T}$ & $\mathrm{Y}$ & $\mathrm{T}$ & $\mathrm{Y}$ & $\mathrm{T}$ & $\mathrm{T}$ & $\mathrm{T}$ & $\mathrm{T}$ & $\mathrm{T}$ & $\mathrm{T}$ \\
\hline 33 & $\mathrm{~T}$ & $\mathrm{Y}$ & $\mathrm{T}$ & $\mathrm{Y}$ & $\mathrm{T}$ & $\mathrm{T}$ & Y & $\mathrm{T}$ & $\mathrm{T}$ & $\mathrm{T}$ & $\mathrm{T}$ & $\mathrm{T}$ \\
\hline
\end{tabular}


$\begin{array}{lllllllllllll}34 & \mathrm{Y} & \mathrm{T} & \mathrm{T} & \mathrm{Y} & \mathrm{T} & \mathrm{T} & \mathrm{T} & \mathrm{T} & \mathrm{T} & \mathrm{T} & \mathrm{Y} & \mathrm{T}\end{array}$

$\begin{array}{lllllllllllll}35 & \mathrm{Y} & \mathrm{T} & \mathrm{T} & \mathrm{Y} & \mathrm{T} & \mathrm{T} & \mathrm{T} & \mathrm{T} & \mathrm{Y} & \mathrm{T} & \mathrm{T} & \mathrm{T}\end{array}$

$\begin{array}{lllllllllllll}36 & \mathrm{Y} & \mathrm{T} & \mathrm{Y} & \mathrm{T} & \mathrm{T} & \mathrm{T} & \mathrm{T} & \mathrm{T} & \mathrm{T} & \mathrm{T} & \mathrm{T} & \mathrm{Y}\end{array}$

$\begin{array}{lllllllllllll}37 & \mathrm{Y} & \mathrm{T} & \mathrm{Y} & \mathrm{T} & \mathrm{Y} & \mathrm{T} & \mathrm{T} & \mathrm{T} & \mathrm{T} & \mathrm{T} & \mathrm{T} & \mathrm{T}\end{array}$

$\begin{array}{lllllllllllll}38 & \mathrm{~T} & \mathrm{Y} & \mathrm{Y} & \mathrm{T} & \mathrm{T} & \mathrm{T} & \mathrm{T} & \mathrm{Y} & \mathrm{T} & \mathrm{T} & \mathrm{T} & \mathrm{T}\end{array}$

$\begin{array}{lllllllllllll}39 & \mathrm{~T} & \mathrm{Y} & \mathrm{Y} & \mathrm{T} & \mathrm{T} & \mathrm{T} & \mathrm{T} & \mathrm{T} & \mathrm{T} & \mathrm{Y} & \mathrm{T} & \mathrm{T}\end{array}$

$\begin{array}{lllllllllllll}40 & \mathrm{~T} & \mathrm{Y} & \mathrm{T} & \mathrm{Y} & \mathrm{T} & \mathrm{Y} & \mathrm{T} & \mathrm{T} & \mathrm{T} & \mathrm{T} & \mathrm{T} & \mathrm{T}\end{array}$

$\begin{array}{lllllllllllll}41 & \mathrm{~T} & \mathrm{Y} & \mathrm{T} & \mathrm{Y} & \mathrm{T} & \mathrm{T} & \mathrm{Y} & \mathrm{T} & \mathrm{T} & \mathrm{T} & \mathrm{T} & \mathrm{T}\end{array}$

$\begin{array}{lllllllllllll}42 & \mathrm{Y} & \mathrm{T} & \mathrm{T} & \mathrm{Y} & \mathrm{T} & \mathrm{T} & \mathrm{T} & \mathrm{T} & \mathrm{T} & \mathrm{T} & \mathrm{Y} & \mathrm{T}\end{array}$

$\begin{array}{lllllllllllll}43 & \mathrm{Y} & \mathrm{T} & \mathrm{T} & \mathrm{Y} & \mathrm{T} & \mathrm{T} & \mathrm{Y} & \mathrm{T} & \mathrm{T} & \mathrm{T} & \mathrm{T} & \mathrm{T}\end{array}$

$\begin{array}{lllllllllllll}44 & \mathrm{Y} & \mathrm{T} & \mathrm{Y} & \mathrm{T} & \mathrm{T} & \mathrm{T} & \mathrm{T} & \mathrm{T} & \mathrm{T} & \mathrm{T} & \mathrm{Y} & \mathrm{T}\end{array}$

$\begin{array}{lllllllllllll}45 & \mathrm{Y} & \mathrm{T} & \mathrm{Y} & \mathrm{T} & \mathrm{T} & \mathrm{T} & \mathrm{T} & \mathrm{T} & \mathrm{Y} & \mathrm{T} & \mathrm{T} & \mathrm{T}\end{array}$

$\begin{array}{lllllllllllll}46 & \mathrm{~T} & \mathrm{Y} & \mathrm{Y} & \mathrm{T} & \mathrm{T} & \mathrm{T} & \mathrm{T} & \mathrm{T} & \mathrm{T} & \mathrm{T} & \mathrm{T} & \mathrm{Y}\end{array}$

$\begin{array}{lllllllllllll}47 & \mathrm{~T} & \mathrm{Y} & \mathrm{Y} & \mathrm{T} & \mathrm{Y} & \mathrm{T} & \mathrm{T} & \mathrm{T} & \mathrm{T} & \mathrm{T} & \mathrm{T} & \mathrm{T}\end{array}$

$\begin{array}{lllllllllllll}48 & \mathrm{~T} & \mathrm{Y} & \mathrm{T} & \mathrm{Y} & \mathrm{T} & \mathrm{T} & \mathrm{T} & \mathrm{Y} & \mathrm{T} & \mathrm{T} & \mathrm{T} & \mathrm{T}\end{array}$

$\begin{array}{lllllllllllll}49 & \mathrm{~T} & \mathrm{Y} & \mathrm{T} & \mathrm{Y} & \mathrm{T} & \mathrm{T} & \mathrm{T} & \mathrm{T} & \mathrm{T} & \mathrm{Y} & \mathrm{T} & \mathrm{T}\end{array}$

$\begin{array}{lllllllllllll}50 & \mathrm{Y} & \mathrm{T} & \mathrm{T} & \mathrm{Y} & \mathrm{T} & \mathrm{Y} & \mathrm{T} & \mathrm{T} & \mathrm{T} & \mathrm{T} & \mathrm{T} & \mathrm{T}\end{array}$

$\begin{array}{lllllllllllll}51 & \mathrm{Y} & \mathrm{T} & \mathrm{T} & \mathrm{Y} & \mathrm{T} & \mathrm{T} & \mathrm{T} & \mathrm{Y} & \mathrm{T} & \mathrm{T} & \mathrm{T} & \mathrm{T}\end{array}$

$\begin{array}{lllllllllllll}52 & \mathrm{Y} & \mathrm{T} & \mathrm{Y} & \mathrm{T} & \mathrm{T} & \mathrm{T} & \mathrm{T} & \mathrm{T} & \mathrm{T} & \mathrm{Y} & \mathrm{T} & \mathrm{T}\end{array}$

$\begin{array}{lllllllllllll}53 & \mathrm{Y} & \mathrm{T} & \mathrm{Y} & \mathrm{T} & \mathrm{Y} & \mathrm{T} & \mathrm{T} & \mathrm{T} & \mathrm{T} & \mathrm{T} & \mathrm{T} & \mathrm{T}\end{array}$

$\begin{array}{lllllllllllll}54 & \mathrm{~T} & \mathrm{Y} & \mathrm{Y} & \mathrm{T} & \mathrm{T} & \mathrm{T} & \mathrm{T} & \mathrm{T} & \mathrm{Y} & \mathrm{T} & \mathrm{T} & \mathrm{T}\end{array}$

$\begin{array}{lllllllllllll}55 & \mathrm{~T} & \mathrm{Y} & \mathrm{Y} & \mathrm{T} & \mathrm{T} & \mathrm{T} & \mathrm{T} & \mathrm{T} & \mathrm{T} & \mathrm{T} & \mathrm{T} & \mathrm{Y}\end{array}$

$\begin{array}{lllllllllllll}56 & \mathrm{~T} & \mathrm{Y} & \mathrm{Y} & \mathrm{T} & \mathrm{Y} & \mathrm{T} & \mathrm{T} & \mathrm{T} & \mathrm{T} & \mathrm{T} & \mathrm{T} & \mathrm{T}\end{array}$

$\begin{array}{lllllllllllll}57 & \mathrm{~T} & \mathrm{Y} & \mathrm{Y} & \mathrm{T} & \mathrm{T} & \mathrm{T} & \mathrm{T} & \mathrm{Y} & \mathrm{T} & \mathrm{T} & \mathrm{T} & \mathrm{T}\end{array}$

$\begin{array}{lllllllllllll}58 & \mathrm{Y} & \mathrm{T} & \mathrm{Y} & \mathrm{T} & \mathrm{T} & \mathrm{T} & \mathrm{T} & \mathrm{T} & \mathrm{T} & \mathrm{Y} & \mathrm{T} & \mathrm{T}\end{array}$

$\begin{array}{lllllllllllll}59 & \mathrm{Y} & \mathrm{T} & \mathrm{T} & \mathrm{Y} & \mathrm{T} & \mathrm{Y} & \mathrm{T} & \mathrm{T} & \mathrm{T} & \mathrm{T} & \mathrm{T} & \mathrm{T}\end{array}$

$\begin{array}{lllllllllllll}60 & \mathrm{Y} & \mathrm{T} & \mathrm{T} & \mathrm{Y} & \mathrm{T} & \mathrm{T} & \mathrm{Y} & \mathrm{T} & \mathrm{T} & \mathrm{T} & \mathrm{T} & \mathrm{T}\end{array}$

$\begin{array}{lllllllllllll}61 & \mathrm{~T} & \mathrm{Y} & \mathrm{T} & \mathrm{Y} & \mathrm{T} & \mathrm{T} & \mathrm{T} & \mathrm{T} & \mathrm{T} & \mathrm{T} & \mathrm{Y} & \mathrm{T}\end{array}$

$\begin{array}{lllllllllllll}62 & \mathrm{~T} & \mathrm{Y} & \mathrm{T} & \mathrm{Y} & \mathrm{T} & \mathrm{T} & \mathrm{T} & \mathrm{T} & \mathrm{Y} & \mathrm{T} & \mathrm{T} & \mathrm{T}\end{array}$

$\begin{array}{lllllllllllll}63 & \mathrm{~T} & \mathrm{Y} & \mathrm{Y} & \mathrm{T} & \mathrm{T} & \mathrm{T} & \mathrm{T} & \mathrm{T} & \mathrm{T} & \mathrm{T} & \mathrm{T} & \mathrm{Y}\end{array}$

$\begin{array}{lllllllllllll}64 & \mathrm{Y} & \mathrm{T} & \mathrm{Y} & \mathrm{T} & \mathrm{Y} & \mathrm{T} & \mathrm{T} & \mathrm{T} & \mathrm{T} & \mathrm{T} & \mathrm{T} & \mathrm{T}\end{array}$

$\begin{array}{lllllllllllll}65 & \mathrm{Y} & \mathrm{T} & \mathrm{Y} & \mathrm{T} & \mathrm{T} & \mathrm{T} & \mathrm{T} & \mathrm{Y} & \mathrm{T} & \mathrm{T} & \mathrm{T} & \mathrm{T}\end{array}$

$\begin{array}{lllllllllllll}66 & \mathrm{Y} & \mathrm{T} & \mathrm{Y} & \mathrm{T} & \mathrm{T} & \mathrm{T} & \mathrm{T} & \mathrm{T} & \mathrm{T} & \mathrm{Y} & \mathrm{T} & \mathrm{T}\end{array}$

$\begin{array}{lllllllllllll}67 & \mathrm{~T} & \mathrm{Y} & \mathrm{T} & \mathrm{Y} & \mathrm{T} & \mathrm{Y} & \mathrm{T} & \mathrm{T} & \mathrm{T} & \mathrm{T} & \mathrm{T} & \mathrm{T}\end{array}$

$\begin{array}{lllllllllllll}68 & \mathrm{~T} & \mathrm{Y} & \mathrm{T} & \mathrm{Y} & \mathrm{T} & \mathrm{T} & \mathrm{Y} & \mathrm{T} & \mathrm{T} & \mathrm{T} & \mathrm{T} & \mathrm{T}\end{array}$

$\begin{array}{lllllllllllll}69 & \mathrm{~T} & \mathrm{Y} & \mathrm{Y} & \mathrm{T} & \mathrm{T} & \mathrm{T} & \mathrm{T} & \mathrm{Y} & \mathrm{T} & \mathrm{T} & \mathrm{T} & \mathrm{T}\end{array}$

$\begin{array}{lllllllllllll}70 & \mathrm{Y} & \mathrm{T} & \mathrm{Y} & \mathrm{T} & \mathrm{T} & \mathrm{T} & \mathrm{T} & \mathrm{T} & \mathrm{T} & \mathrm{Y} & \mathrm{T} & \mathrm{T}\end{array}$

$\begin{array}{lllllllllllll}71 & \mathrm{Y} & \mathrm{T} & \mathrm{T} & \mathrm{Y} & \mathrm{Y} & \mathrm{T} & \mathrm{T} & \mathrm{T} & \mathrm{T} & \mathrm{T} & \mathrm{T} & \mathrm{T}\end{array}$

$\begin{array}{lllllllllllll}72 & \mathrm{Y} & \mathrm{T} & \mathrm{T} & \mathrm{Y} & \mathrm{T} & \mathrm{T} & \mathrm{T} & \mathrm{T} & \mathrm{Y} & \mathrm{T} & \mathrm{T} & \mathrm{T}\end{array}$

$\begin{array}{lllllllllllll}73 & \mathrm{Y} & \mathrm{T} & \mathrm{T} & \mathrm{Y} & \mathrm{T} & \mathrm{T} & \mathrm{T} & \mathrm{T} & \mathrm{T} & \mathrm{T} & \mathrm{T} & \mathrm{Y}\end{array}$

$\begin{array}{lllllllllllll}74 & \mathrm{~T} & \mathrm{Y} & \mathrm{Y} & \mathrm{T} & \mathrm{Y} & \mathrm{T} & \mathrm{T} & \mathrm{T} & \mathrm{T} & \mathrm{T} & \mathrm{T} & \mathrm{T}\end{array}$

$\begin{array}{lllllllllllll}75 & \mathrm{~T} & \mathrm{Y} & \mathrm{Y} & \mathrm{T} & \mathrm{T} & \mathrm{T} & \mathrm{T} & \mathrm{Y} & \mathrm{T} & \mathrm{T} & \mathrm{T} & \mathrm{T}\end{array}$

$\begin{array}{lllllllllllll}76 & \mathrm{~T} & \mathrm{Y} & \mathrm{Y} & \mathrm{T} & \mathrm{T} & \mathrm{T} & \mathrm{T} & \mathrm{T} & \mathrm{T} & \mathrm{Y} & \mathrm{T} & \mathrm{T}\end{array}$

$\begin{array}{lllllllllllll}77 & \mathrm{~T} & \mathrm{Y} & \mathrm{Y} & \mathrm{T} & \mathrm{T} & \mathrm{Y} & \mathrm{T} & \mathrm{T} & \mathrm{T} & \mathrm{T} & \mathrm{T} & \mathrm{T}\end{array}$

$\begin{array}{llllllllllllll}78 & \mathrm{~T} & \mathrm{Y} & \mathrm{T} & \mathrm{Y} & \mathrm{T} & \mathrm{T} & \mathrm{Y} & \mathrm{T} & \mathrm{T} & \mathrm{T} & \mathrm{T} & \mathrm{T}\end{array}$ 


\begin{tabular}{lllllllllllll}
79 & $\mathrm{Y}$ & $\mathrm{T}$ & $\mathrm{T}$ & $\mathrm{Y}$ & $\mathrm{T}$ & $\mathrm{T}$ & $\mathrm{T}$ & $\mathrm{T}$ & $\mathrm{T}$ & $\mathrm{T}$ & $\mathrm{Y}$ & $\mathrm{T}$ \\
80 & $\mathrm{Y}$ & $\mathrm{T}$ & $\mathrm{T}$ & $\mathrm{Y}$ & $\mathrm{T}$ & $\mathrm{T}$ & $\mathrm{T}$ & $\mathrm{T}$ & $\mathrm{Y}$ & $\mathrm{T}$ & $\mathrm{T}$ & $\mathrm{T}$ \\
81 & $\mathrm{Y}$ & $\mathrm{T}$ & $\mathrm{T}$ & $\mathrm{Y}$ & $\mathrm{T}$ & $\mathrm{T}$ & $\mathrm{T}$ & $\mathrm{T}$ & $\mathrm{T}$ & $\mathrm{T}$ & $\mathrm{T}$ & $\mathrm{Y}$ \\
82 & $\mathrm{Y}$ & $\mathrm{T}$ & $\mathrm{T}$ & $\mathrm{Y}$ & $\mathrm{Y}$ & $\mathrm{T}$ & $\mathrm{T}$ & $\mathrm{T}$ & $\mathrm{T}$ & $\mathrm{T}$ & $\mathrm{T}$ & $\mathrm{T}$ \\
83 & $\mathrm{~T}$ & $\mathrm{Y}$ & $\mathrm{Y}$ & $\mathrm{T}$ & $\mathrm{T}$ & $\mathrm{T}$ & $\mathrm{T}$ & $\mathrm{Y}$ & $\mathrm{T}$ & $\mathrm{T}$ & $\mathrm{T}$ & $\mathrm{T}$ \\
84 & $\mathrm{~T}$ & $\mathrm{Y}$ & $\mathrm{Y}$ & $\mathrm{T}$ & $\mathrm{T}$ & $\mathrm{T}$ & $\mathrm{T}$ & $\mathrm{Y}$ & $\mathrm{T}$ & $\mathrm{T}$ & $\mathrm{T}$ & $\mathrm{T}$ \\
85 & $\mathrm{Y}$ & $\mathrm{T}$ & $\mathrm{Y}$ & $\mathrm{T}$ & $\mathrm{T}$ & $\mathrm{T}$ & $\mathrm{T}$ & $\mathrm{T}$ & $\mathrm{T}$ & $\mathrm{Y}$ & $\mathrm{T}$ & $\mathrm{T}$ \\
86 & $\mathrm{~T}$ & $\mathrm{Y}$ & $\mathrm{Y}$ & $\mathrm{T}$ & $\mathrm{Y}$ & $\mathrm{T}$ & $\mathrm{T}$ & $\mathrm{T}$ & $\mathrm{T}$ & $\mathrm{T}$ & $\mathrm{T}$ & $\mathrm{T}$ \\
87 & $\mathrm{Y}$ & $\mathrm{T}$ & $\mathrm{T}$ & $\mathrm{Y}$ & $\mathrm{T}$ & $\mathrm{T}$ & $\mathrm{T}$ & $\mathrm{T}$ & $\mathrm{Y}$ & $\mathrm{T}$ & $\mathrm{T}$ & $\mathrm{T}$ \\
88 & $\mathrm{Y}$ & $\mathrm{T}$ & $\mathrm{T}$ & $\mathrm{Y}$ & $\mathrm{T}$ & $\mathrm{T}$ & $\mathrm{T}$ & $\mathrm{T}$ & $\mathrm{T}$ & $\mathrm{T}$ & $\mathrm{T}$ & $\mathrm{Y}$ \\
89 & $\mathrm{~T}$ & $\mathrm{Y}$ & $\mathrm{Y}$ & $\mathrm{T}$ & $\mathrm{Y}$ & $\mathrm{T}$ & $\mathrm{T}$ & $\mathrm{T}$ & $\mathrm{T}$ & $\mathrm{T}$ & $\mathrm{T}$ & $\mathrm{T}$ \\
90 & $\mathrm{~T}$ & $\mathrm{Y}$ & $\mathrm{Y}$ & $\mathrm{T}$ & $\mathrm{T}$ & $\mathrm{T}$ & $\mathrm{T}$ & $\mathrm{Y}$ & $\mathrm{T}$ & $\mathrm{T}$ & $\mathrm{T}$ & $\mathrm{T}$ \\
91 & $\mathrm{~T}$ & $\mathrm{Y}$ & $\mathrm{Y}$ & $\mathrm{T}$ & $\mathrm{T}$ & $\mathrm{T}$ & $\mathrm{T}$ & $\mathrm{T}$ & $\mathrm{T}$ & $\mathrm{Y}$ & $\mathrm{T}$ & $\mathrm{T}$ \\
92 & $\mathrm{~T}$ & $\mathrm{Y}$ & $\mathrm{Y}$ & $\mathrm{T}$ & $\mathrm{T}$ & $\mathrm{Y}$ & $\mathrm{T}$ & $\mathrm{T}$ & $\mathrm{T}$ & $\mathrm{T}$ & $\mathrm{T}$ & $\mathrm{T}$ \\
93 & $\mathrm{Y}$ & $\mathrm{T}$ & $\mathrm{T}$ & $\mathrm{Y}$ & $\mathrm{T}$ & $\mathrm{T}$ & $\mathrm{Y}$ & $\mathrm{T}$ & $\mathrm{T}$ & $\mathrm{T}$ & $\mathrm{T}$ & $\mathrm{T}$ \\
94 & $\mathrm{Y}$ & $\mathrm{T}$ & $\mathrm{T}$ & $\mathrm{Y}$ & $\mathrm{T}$ & $\mathrm{T}$ & $\mathrm{T}$ & $\mathrm{T}$ & $\mathrm{T}$ & $\mathrm{T}$ & $\mathrm{Y}$ & $\mathrm{T}$ \\
95 & $\mathrm{Y}$ & $\mathrm{T}$ & $\mathrm{Y}$ & $\mathrm{T}$ & $\mathrm{T}$ & $\mathrm{T}$ & $\mathrm{T}$ & $\mathrm{T}$ & $\mathrm{Y}$ & $\mathrm{T}$ & $\mathrm{T}$ & $\mathrm{T}$ \\
96 & $\mathrm{Y}$ & $\mathrm{T}$ & $\mathrm{T}$ & $\mathrm{Y}$ & $\mathrm{T}$ & $\mathrm{T}$ & $\mathrm{T}$ & $\mathrm{T}$ & $\mathrm{T}$ & $\mathrm{T}$ & $\mathrm{T}$ & $\mathrm{Y}$ \\
97 & $\mathrm{~T}$ & $\mathrm{Y}$ & $\mathrm{Y}$ & $\mathrm{T}$ & $\mathrm{Y}$ & $\mathrm{T}$ & $\mathrm{T}$ & $\mathrm{T}$ & $\mathrm{T}$ & $\mathrm{T}$ & $\mathrm{T}$ & $\mathrm{T}$ \\
98 & $\mathrm{~T}$ & $\mathrm{Y}$ & $\mathrm{Y}$ & $\mathrm{T}$ & $\mathrm{T}$ & $\mathrm{T}$ & $\mathrm{T}$ & $\mathrm{Y}$ & $\mathrm{T}$ & $\mathrm{T}$ & $\mathrm{T}$ & $\mathrm{T}$ \\
99 & $\mathrm{~T}$ & $\mathrm{Y}$ & $\mathrm{T}$ & $\mathrm{Y}$ & $\mathrm{T}$ & $\mathrm{T}$ & $\mathrm{T}$ & $\mathrm{T}$ & $\mathrm{T}$ & $\mathrm{Y}$ & $\mathrm{T}$ & $\mathrm{T}$ \\
100 & $\mathrm{Y}$ & $\mathrm{T}$ & $\mathrm{T}$ & $\mathrm{Y}$ & $\mathrm{T}$ & $\mathrm{Y}$ & $\mathrm{T}$ & $\mathrm{T}$ & $\mathrm{T}$ & $\mathrm{T}$ & $\mathrm{T}$ & $\mathrm{T}$ \\
\hline $\mathbf{J M L}$ & $\mathbf{5 1}$ & $\mathbf{4 9}$ & $\mathbf{5 5}$ & $\mathbf{4 5}$ & $\mathbf{1 8}$ & $\mathbf{1 0}$ & $\mathbf{9}$ & $\mathbf{1 6}$ & $\mathbf{1 2}$ & $\mathbf{1 5}$ & $\mathbf{8}$ & $\mathbf{1 2}$ \\
\hline
\end{tabular}

Keterangan:

Jekel : Jenis Kelamin, merupakan jenis kelamin mahasiswa baru, dimana L berarti Laki-laki dan P berarti Perempuan.

Kelas $\quad$ : Kelas adalah pilihan kelas mahasiswa baru, yaitu Kelas A dan Kelas B.

Kecamatan : Yaitu kecamatan asal mahasiswa baru tersebut berasal, yaitu:

MBL : Muara Bulian

PMY : Pemayung

BJB : Bajubang

MTS : Muara Tembesi

MRS : Mersam

MSI : Maro Sebo Ilir

MSU : Maro Sebo Ulu

BTN : Batin XXIV

Dari data di atas, transaksi dengan variabel huruf Y berarti sebagai YA, sedangkan huruf T menyatakan tidak. Dapat dilihat bahwa jumlah mahasiswa jenis kelamin Laki-laki sebanyak 51 orang, dan Perempuan 49 orang. Mahasiswa baru memilih kelas A sebanyak 55 orang, dan kelas B 45 orang. Mahasiswa baru yang berasal dari Kecamatan Muara Bulian sebanyak 18, Pemayung 10, Bajubang 9, Muara Tembesi 16, Mersam 12, Maro Sebo Ilir 15, Maro Sebo Ulu 8 dan Batin XXIV 12 orang.

Dengan mengacu pada tabel di atas, dapat kita lihat nilai support setiap transaksi, sebagaimana tabel berikut. 
Tabel 3. Nilai Support

\begin{tabular}{llcc}
\hline & Variabel & Frekuensi & Support \\
\hline \multirow{2}{*}{ Jenis Kelamin } & L & 51 & $51 \%$ \\
& P & 49 & $49 \%$ \\
\hline \multirow{2}{*}{ Kelas } & A & 55 & $55 \%$ \\
& B & 45 & $45 \%$ \\
\hline \multirow{5}{*}{ Kecamatan } & Muara Bulian & 18 & $18 \%$ \\
& Pemayung & 10 & $10 \%$ \\
& Bajubang & 9 & $9 \%$ \\
& Muara Tembesi & 16 & $16 \%$ \\
& Mersam & 12 & $12 \%$ \\
& Maro Sebo Ilir & 15 & $15 \%$ \\
& Maro Sebo Ulu & 8 & $8 \%$ \\
& Batin XXIV & 12 & $12 \%$ \\
\hline
\end{tabular}

\subsection{Pengujian Pada Software Data Mining Weka}

Berikut adalah langkah-langkah pengujian.

1. Buka aplikasi Weka, sebagaimana gambar berikut.

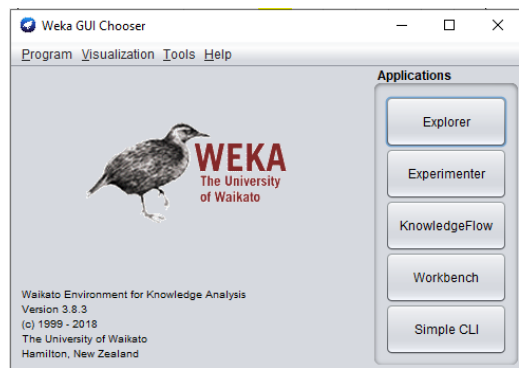

Gambar 3. Interface Weka

2. Pemanggilan data melalui menu Explore.

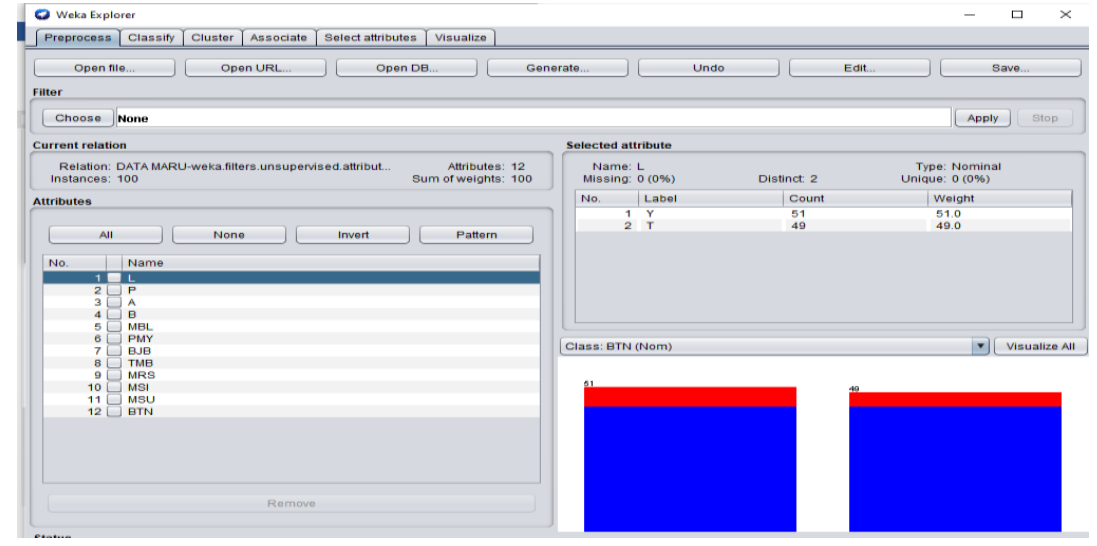

Gambar 4. Pemanggilan Data 
3. Memilih menu Associate dan algoritma Apriori dan rule yang terbentuk.

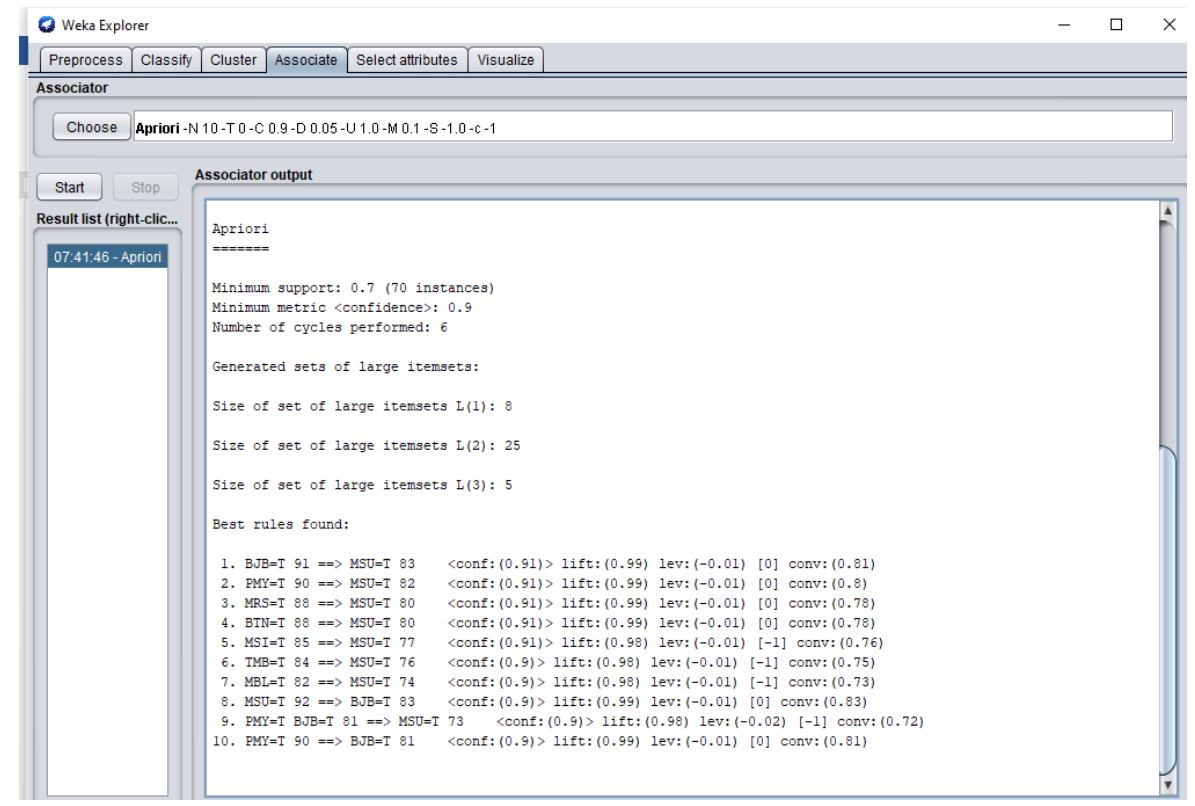

Gambar 5. Rule yang terbentuk dari Algoritma Apriori

\section{Kesimpulan}

Berdasarkan pembahasan di atas, kesimpulan yang dapat diambil adalah Algoritma Apriori memiliki kecepatan dalam pemrosesan data asosiasi. Pengujian menggunakan software data mining Weka didapatkan 10 rule terbaik. Dengan fokus pada kecamatan asal mahasiswa baru tersebut, maka kombinasi yang didapat adalah Jika mahasiswa baru tidak berasal dari Kecamatan Pemayung dan Bajubang sebanyak 1 orang, maka juga tidak berasal dari Kecamatan Maro Sebo Ulu sebanyak 73 orang dengan tingkat confidence $90 \%$.

\section{Daftar Pustaka}

[1] A. Anas, "Penerapan Algoritma Fp-Growth Dalam Menentukan Perilaku Konsumen Ghania Mart Muara Bulian," J. Ilm. Media Sisfo, vol. 14, no. 2, p. 120, 2020, doi: 10.33998/mediasisfo.2020.14.2.879.

[2] S. Heni and A. Irham Gufroni, "Penerapan Data Mining Dalam Pengelompokan Penderita Thalassaemia," J. Nas. Teknol. dan Sist. Inf., vol. 03, no. 02, pp. 299-305, 2017.

[3] E. Widiati and K. Evita Dewi, "Implementasi Association Rule Terhadap Penyusunan Layout Makanan Dan Penentuan Paket Makanan Hemat Di Rm Roso Echo Dengan Algoritma Apriori," J. Ilm. Komput. dan Inform., vol. 96, no. 2, pp. 2089-9033, 2014.

[4] A. Anas and B. Darma, "Analisis Dosen Favorit STIE-GK Muara Bulian Menggunakan Algoritma Apriori," vol. 13, no. 2, 2019.

[5] K. Tampubolon, H. Saragih, B. Reza, K. Epicentrum, A. Asosiasi, and A. Apriori, "Implementasi Data Mining Algoritma Apriori Pada Sistem Persediaan Alat-Alat Kesehatan,” pp. 93-106, 2013.

[6] W. Choiriah, "Penggunaan Algorithma Apriori Data Mining Untuk Mengetahui Tingkatkesetiaan Konsumen ( Brand Loyality ) Terhadap Merek Kenderaan Bermotor ( Studi Kasus Dealer Honda Rumbai )," Pengguna. Algoritm. Apriori Data Min. Untuk Mengetahui Tingkat Kesetiaan Konsum. (Brand Loyal. Terhadap Merek Kenderaan Bermotor (Studi Kasus Deal. Honda Rumbai), vol. 7, no. 1, pp. 44-52, 2016.

[7] D. Anggraini, S. A. Putri, and L. A. Utami, "Implementasi Algoritma Apriori Dalam Menentukan Penjualan Mobil Yang Paling Diminati Pada Honda Permata Serpong," J. Media Inform. Budidarma, vol. 4, no. 2, p. 302, 2020, doi: 10.30865/mib.v4i2.1496.

[8] L. Kurniawati, A. E. Kusuma, and B. Dewansyah, "Implementasi Algoritma Apriori Untuk Menentukan Stok Obat," vol. 4, no. 1, pp. 6-10, 2019.

[9] D. K. Pane, "Implementasi Data Mining Pada Penjualan Produk Elektronik Dengan Algoritma Apriori ( Studi Kasus : Kreditplus ),” Pelita Inform. Budi Darma, vol. valume : I, pp. 25-29, 2013, doi: 2301- 
9425.

[10] F. A. K. Wardani and T. Kristiana, "Implementasi Data Mining Penjualan Produk Kosmetik Pada PT. Natural Nusantara Menggunakan Algoritma Apriori," Paradig. - J. Komput. dan Inform., vol. 22, no. 1, pp. 85-90, 2020, doi: 10.31294/p.v22i1.6520. 